ARTIGOS

\title{
POLÍTICAS PÚBLICAS NO BRASIL: O CASO DO PROGRAMA DE AQUISIÇÃO DE ALIMENTOS DA AGRICULTURA FAMILIAR NO ESTADO DE SÃO PAULO, BRASIL
}

Jonatan Alexandre de Oliveira ${ }^{1}$

Universidade Estadual Paulista

José Giacomo Baccarin²

Universidade Estadual Paulista

Enviado em 4 ago. 2017 | Aceito em 19 jan. 2020

Resumo: Tem-se como principal objetivo analisar a organização do Programa de Aquisição de Alimentos da Agricultura Familiar (PAA) no espaço agrícola do estado de São Paulo, Brasil. Utilizamos como fonte de dados as ações da superintendência da Companhia Nacional de Abastecimento CONAB-SP (2012). De acordo com as ações do PAA no espaço agrícola paulista, constatou-se que o PAA apresentou desempenho relativo melhor que o conjunto das outras superintendências regionais; a modalidade Compra com Doação Simultânea atinge número mais expressivo de municípios; o PAA vem sendo aplicado com maior intensidade em favor dos agricultores familiares e assentados de regiões administrativas mais empobrecidas; há forte vínculo do PAA com os assentamentos de reforma agrária; o PAA parece complementar o PRONAF, na medida em que atende com maior intensidade justamente aqueles agricultores com maiores dificuldades de acesso ao programa de crédito rural. Levando-se em conta as intenções expressas formalmente na criação do PAA, em especial aquela de procurar atender os agricultores familiares com menor renda, as análises deste trabalho apontam que a mesma vem sendo cumprida no caso do estado de São Paulo, embora os recursos do Programa e o número de agricultores familiares ainda seja reduzido em relação ao seu público potencial.

Palavras chave: Organização Espacial; Regiões Administrativas; Políticas Públicas; Agricultura Familiar

\section{PUBLIC POLICIES IN BRAZIL: THE CASE OF THE PROGRAM OF ACQUISITION OF FOODS OF FAMILY AGRICULTURE IN THE}

\section{STATE OF SÃO PAULO, BRAZIL}

Abstract: The main objective is to analyze the organization of the Program of Acquisition of Food of Family Agriculture (PAA) in the agricultural space of the state of São Paulo, Brazil. We used as data source the actions of the Superintendence of National Supply Company CONAB-SP (2012). According with the actions of the PAA in the agricultural space of São Paulo, it was verified that the PAA presented a relative better performance in relation to the set of other regional superintendence; the Buy with Simultaneous Donation modality reaches the most expressive number of municipalities; the PAA has been applied with greater intensity in favor of the family farmers and settlers of more impoverished administrative regions; There is a strong link between the PAA and the agrarian settlements; the PAA seems to complement PRONAF, since is responds with greater intensity to those farmers with greater difficulties of access to the rural credit program. Taking into account the intentions expressed formally in the creation of the PAA, especially that of seeking to provide the lowest income family farmers. The analyzes of this work indicate that it has been fulfilled in the case of the state of São Paulo. Although the resources of the Program and the number of family farmers is still small relative to its potential audience

Keywords: Space Organization; Administrative Regions; Public Policy; Family Farming.

\section{POLÍTICAS PÚBLICAS EN BRASIL: EL CASO DEL PROGRAMADE ADQUISICIÓN DE ALIMENTOS PARA LA AGRICULTURA FAMILIAR EN EL ESTADO DE SÃO PAULO, BRASIL}

Resumen: El objetivo principal es analizar la organización del Programa de Adquisición de Alimentos para la Agricultura Familiar (PAA) en el espacio agrícola del estado de São Paulo, Brasil. Utilizamos como fuente de datos las acciones de la superintendencia de la Compañía Nacional de Abastecimiento CONAB-SP (2012). Según las acciones del PAA en el espacio agrícola en São Paulo, se descubrió que el PAA tuvo un desempeño relativamente mejor que el conjunto de otras superintendencias regionales; la modalidad de Compra con Donación Simultánea llega a un mayor número de municipios; El PAA se ha aplicado con mayor intensidad a favor de los agricultores familiares y los asentados de regiones administrativas más empobrecidas; existe un fuerte vínculo entre el PAA y los asentamientos de reforma agraria; el

1. Doutor em Geografia. Bolsista DTI-A CNpq. E-mail: jonatan.oliveira@unesp.br. ORCID: https://orcid.org/0000-0002-23265912.

2. Professor livre docente da Universidade Estadual Paulista. E-mail:jose.baccarin@unesp.br. ORCID: https://orcid.org/00000002-8120-3621. 
PAA parece complementar al PRONAF, en la medida en que sirve con mayor intensidad precisamente a aquellos agricultores con mayores dificultades para acceder al programa de crédito rural. Teniendo en cuenta las intenciones expresadas formalmente en la creación del PAA, especialmente la de tratar de servir a los agricultores familiares con menores ingresos, los análisis de este trabajo muestran que se ha cumplido en el caso del estado de São Paulo, aunque los recursos del El programa y el número de agricultores familiares todavía se reducen en relación con su audiencia potencial.

Palabras clave: Organización espacial, Regiones Administrativas, Políticas públicas, Agricultura familiar

*

Introdução

O estudo justifica-se perante as mudanças na orientação de políticas públicas voltadas para a agricultura brasileira, que, em seu esforço modernizante, entre 1960 e meados dos anos 1990, praticamente, desconsiderou as especificidades e necessidades próprias da agricultura familiar (ANDRADE, 1979; GRAZIANO DA SILVA, 1981; MARAFON, 1988; HESPANHOL, 2000). Tal situação sofreu relativa alteração em 1996, quando a agricultura familiar teve seu reconhecimento intensificado com a criação do Programa Nacional de Fortalecimento da Agricultura Familiar (PRONAF), destinado ao fornecimento de créditos de investimento e custeio com juros menores dos que os praticados para a chamada agricultura empresarial. Contribuíram para isso a diminuição abrupta da renda que atingiu toda a agricultura brasileira na esteira da valorização do Real, entre 1995 e 1996, o aumento dos conflitos fundiários, com registros de dezenas de mortes, obrigando maior intervenção pública, bem como a mobilização e reivindicação de agricultores familiares, especialmente da Região Sul, e de cientistas sociais em favor da instituição de programas específicos.

O escopo de programas voltados para a agricultura familiar aumentou em 2003, no âmbito do Programa Fome Zero, ao se instituir, pelo artigo 19 da Lei no 10.696, de 2 de julho 2003, o Programa de Aquisição de Alimentos da Agricultura Familiar (PAA), baseado em pagamento de preços maiores dos que os constatados em mercados tradicionais para os agricultores. Com isso, procurava-se aumentar a renda e a inclusão econômica e social dos agricultores familiares, criando novos canais de comercialização. Ao mesmo tempo, os alimentos adquiridos pelo poder público deveriam ser destinado ao consumo de parcelas da população em situação de insegurança alimentar. Como se verá adiante, o PAA é executado através de diversas modalidades, entre elas a Compra com Doação Simultânea e Formação de Estoques.

Tal orientação foi reforçada em 2009, com a regulamentação do Programa Nacional de Alimentação Escolar (PNAE) pela Lei no 11.947, de 16 de junho de 2009, cujo principal intuito é combater as deficiências nutricionais do alunado brasileiro (BRASIL, 2009). O Artigo 14 desta Lei estipula que no mínimo 30\% dos recursos para alimentação escolar recebidos do Fundo Nacional de Desenvolvimento da Educação (FNDE) por governos estaduais e municipais devam ser gastos na compra de produtos de agricultores familiares. Também aqui se prevê que os preços recebidos pelos agricultores sejam mais altos do que os de mercados convencionais.

Voltando-se ao PAA, sua execução com recursos federais, muitas vezes, é feita via convênios ou termos de cooperação estabelecidos com estados e municípios, que ficam responsáveis pela sua operacionalização junto aos agricultores familiares. Também pode ser feita diretamente por órgão federal, sendo executor, nesse caso, a Companhia Nacional de Abastecimento (CONAB), que, com isso, ampliou seu leque de ações, atendendo especificamente agricultores familiares. Até 2003, a CONAB tinha uma atuação mais restrita, associada ao gerenciamento dos estoques de produtos agrícolas e a execução do Programa de Garantia de Preços Mínimos (PGPM), cujos beneficiários, em sua imensa maioria, eram grandes agricultores e empresas dedicadas à venda ou processamento de produtos agrícolas, como agroindústrias e grandes cooperativas. 
O PAA possui um grupo gestor do PAA coordenado pelo Ministério do Desenvolvimento Social e Combate à Fome (MDS) e composto, até o início de 2016, por representantes dos Ministérios do Desenvolvimento Agrário (MDA), da Agricultura, Pecuária e Abastecimento (MAPA), do Planejamento Orçamento e Gestão (MPOG), da Fazenda (MF) e do Ministério da Educação (MEC). O Grupo Gestor, entre outras atividades, define as modalidades e analisar a operacionalização do Programa.

A primeira mudança operacional do PAA ocorreu em 2006, com o início dos aportes orçamentários do MDA, complementando aqueles que desde o início do Programa eram alocados pelo MDS. A modalidade Compra Antecipada Especial da Agricultura Familiar foi separada em duas: Formação de Estoques e Compra com Doação Simultânea a serem executados com recursos, respectivamente do MDA e MDS. A primeira disponibiliza capital de giro para que associações ou cooperativas possam adquirir a produção de agricultores familiares, formando estoques de produtores para serem comercializados quando os preços se mostrarem compensatórios e é operada pela CONAB. Por sua vez, a Compra com Doação Simultânea propicia a compra de alimentos produzidos por agricultores familiares organizados em grupos formais (associações e cooperativas) e a sua doação a entidades da rede de promoção e proteção social. Esta modalidade é operada pela CONAB e por estados e municípios que recebem, via convênio ou termo de cooperação, recursos do MDS.

Mais adiante outras modificações ocorreram, inclusive com a criação de novas modalidade, de forma que em 2016 as modalidades do PAA são

Quadro 1 - Modalidades Programa de Aquisição de Alimentos da Agricultura Familiar

\begin{tabular}{|c|c|c|c|c|}
\hline Modalidades & Forma de acesso & Limite & $\begin{array}{l}\text { Origem do } \\
\text { Recurso }\end{array}$ & Ação \\
\hline \multirow{2}{*}{$\begin{array}{l}\text { Compra da } \\
\text { Agricultura } \\
\text { Familiar para } \\
\text { Doação } \\
\text { Simultânea }\end{array}$} & Individual & $\begin{array}{c}\mathrm{R} \$ 4,5 \\
\mathrm{mil}\end{array}$ & \multirow[b]{2}{*}{ MDS } & \multirow{2}{*}{$\begin{array}{l}\text { Responsável pela doação de produtos adquiridos } \\
\text { da agricultura familiar a pessoas em situação de } \\
\text { insegurança alimentar e nutricional. }\end{array}$} \\
\hline & $\begin{array}{c}\text { Organizações } \\
\text { (cooperativas/associações) }\end{array}$ & $\begin{array}{c}\mathrm{R} \$ 4,8 \\
\text { mil }\end{array}$ & & \\
\hline $\begin{array}{l}\text { Formação de } \\
\text { Estoques pela } \\
\text { Agricultura } \\
\text { Familiar }\end{array}$ & $\begin{array}{c}\text { Organizações } \\
\text { (cooperativas/associações) }\end{array}$ & $\mathrm{R} \$ 8 \mathrm{mil}$ & $\begin{array}{l}\text { MDS/ } \\
\text { MDA }\end{array}$ & $\begin{array}{l}\text { Disponibiliza recursos para que organizações da } \\
\text { agricultura familiar formem estoques de produtos } \\
\text { para posterior comercialização. }\end{array}$ \\
\hline $\begin{array}{l}\text { Compra Direta } \\
\text { da Agricultura } \\
\text { Familiar }\end{array}$ & $\begin{array}{l}\text { Individual ou organizações } \\
\text { (cooperativas/associações) }\end{array}$ & $\mathrm{R} \$ 8 \mathrm{mil}$ & $\begin{array}{l}\text { MDS/ } \\
\text { MDA }\end{array}$ & $\begin{array}{l}\text { Voltada à aquisição de produtos em situação de } \\
\text { baixa de preço ou em função da necessidade de } \\
\text { atender a demandas de alimentos de populações } \\
\text { em condição de insegurança alimentar. }\end{array}$ \\
\hline $\begin{array}{l}\text { Incentivo à } \\
\text { Produção e } \\
\text { Incentivo de } \\
\text { Leite - PAA } \\
\quad \text { Leite }\end{array}$ & $\begin{array}{l}\text { Individual ou organizações } \\
\text { (cooperativas/associações) }\end{array}$ & $\begin{array}{l}\text { R\$ } 4 \text { mil } \\
\text { por } \\
\text { semestre }\end{array}$ & MDS & $\begin{array}{l}\text { Assegura a distribuição gratuita de leite em ações } \\
\text { de combate à fome e à desnutrição de cidadãos } \\
\text { que estejam em situação de vulnerabilidade social } \\
\text { e/ou em estado de insegurança alimentar e } \\
\text { nutricional. Atende os estados do Nordeste. }\end{array}$ \\
\hline $\begin{array}{c}\text { Compra } \\
\text { Institucional }\end{array}$ & $\begin{array}{l}\text { Individual ou organizações } \\
\text { (cooperativas/associações) }\end{array}$ & $\mathrm{R} \$$ $8 \mathrm{mil}$ & - & $\begin{array}{l}\text { Compra voltada para o atendimento de demandas } \\
\text { regulares de consumo de alimentos por parte da } \\
\text { União, Estados, Distrito Federal e Municípios; }\end{array}$ \\
\hline $\begin{array}{l}\text { Aquisição de } \\
\text { Sementes }\end{array}$ & $\begin{array}{l}\text { Individual ou organizações } \\
\text { (cooperativas/associações) }\end{array}$ & $\mathrm{R} \$ 16 \mathrm{mil}$ & MDS & $\begin{array}{l}\text { Compra de sementes, mudas e materiais } \\
\text { propagativos para alimentação humana ou animal } \\
\text { de beneficiários fornecedores para doação a } \\
\text { beneficiários consumidores ou fornecedores. }\end{array}$ \\
\hline
\end{tabular}

Fonte: Elaborado pelo autor, com base nos dados do Ministério do Desenvolvimento Agrário (BRASIL, 2015) 
A grande contribuição do PAA é a capacidade que o Programa tem de atuar em diferentes contextos regionais através de suas modalidades, oferecendo oportunidades de inserção da produção familiar em mercados locais ou regionais, com destaque para o desenvolvimento da modalidade PAA-Leite, especificamente relacionada ao Norte de Minas e a Região Nordeste. Já a Formação de Estoque tende a beneficiar mais os agricultores da região Centro-Sul, que possuem maior organização formal e possuindo maior articulação com os meios técnicos, inclusive com capacidade de armazenamento.

O PAA recomenda a organização dos agricultores familiares em cooperativas ou associações, com objetivo de fortalecer as articulações entre produtores. A cobrança desse requisito visa promover a organização política, social e econômica dos agricultores familiares, sobretudo, atuando na organização de documentos para elaboração de projetos coletivos, reduzindo custos de processamentos e comercialização dos produtos da agricultura familiar.

Outro aspecto a ser destacado do PAA é o valor relativamente baixo que cada agricultor pode receber por ano ao participar do Programa. Tal situação é intencional, tendo-se procurado desde o início instituir uma ação pública que permitisse a participação de agricultores familiares mais empobrecidos e com dificuldades, por exemplo, de enfrentar a burocracia e as exigências financeiras dos contratos de crédito rural do PRONAF.

Ao escolher o estado de São Paulo como região do estudo, não se deve esquecer dos efeitos que a lavoura canavieira exerce sobre o uso de seu solo agrícola e sua estrutura fundiária. No mais das vezes, a cana é cultivada em imensos estabelecimentos agropecuários, englobando, inclusive área arrendada de pequenos agricultores e diminuindo o espaço para outras atividades agropecuárias. Segundo (BACCARIN et al, 2014, p. 9) “Em 2010, a cana-de-açúcar, com seus 5,8 milhões de hectares, ocupava área superior aos 4,1 milhões de hectares, resultados da soma das áreas de todas as demais lavouras, permanentes e temporárias, e das florestas plantadas na agricultura de São Paulo".

Ainda assim, a agricultura familiar do Estado contava, em 2006, com 151.015 estabelecimentos agropecuários, usando área de 2,5 milhões de hectares e ocupando 328.177 pessoas, equivalentes a $36,1 \%$ da força de trabalho na agricultura paulista (IBGE, 2006). Em termos de valor da produção, a agricultura familiar apresentava participação de 15,7\% do valor gerado nos campos paulistas (CORÁ; BELIK, 2012, p. 11). No caso da horticultura essa participação era bem maior, atingindo 41,0\%, destacando-se também as participações na produção do leite, 39,3\%, arroz, 34,1\%, e feijão, 19,9\%, esses três últimos produtos altamente consumidos pela população.

Outro dado pertinente diz respeito à organização e formalização dos agricultores familiares no Estado. Não foi possível encontrar informações sobre o número de associações e de cooperativas dos agricultores familiares paulistas. Entretanto, em 2011 foi constatado, conforme registros do Ministério de Desenvolvimento Agrário (BRASIL, 2012), que 97.717 agricultores familiares apresentaram a Declaração de Aptidão ao PRONAF (DAP) ativa em São Paulo, número expressivo frente aos 151.015 estabelecimentos de agricultura familiar elencados no Censo de 2006.

Entendemos que o PAA procura atender, via aumento de renda, em especial os agricultores mais empobrecidos, e via aumento de consumo, as classes sociais mais pobres e com maior insegurança alimentar e nutricional, este trabalho tem como objetivo verificar se a distribuição do PAA entre as regiões e agricultores familiares do estado e São Paulo guarda correspondência com aquelas duas intenções do Programa. Especificamente, pretende-se comparar para o ano de 2012:

a) A distribuição do PAA entre os municípios paulistas, levando em conta a importância local da agricultura familiar; 
b) A distribuição do PAA entre as Regiões Administrativas (RAs) de São Paulo, levando em consideração seu desenvolvimento econômico e nível de renda;

c) A distribuição do PAA e os assentamentos de Reforma Agrária existentes nas diversas regiões paulistas;

d) A distribuição do PAA e o acesso dos agricultores ao PRONAF;

É importante salientar que os resultados apresentados dizem respeito exclusivamente à ação da Superintendência do Estado de São Paulo da CONAB, que executa as modalidades Formação de Estoques e Compra com Doação Simultânea. Não se estudaram as ações executadas diretamente por municípios paulistas em convênios com o MDS.

\section{Metodologia de pesquisa}

A respeito da metodologia de pesquisa foram consideradas as publicações oficiais do governo, como leis, portarias, relatórios e transparência pública. Esse conjunto de documento permitiu resgatar parte do contexto histórico da agricultura familiar e, sobretudo, identificar as ideias que nortearam a origem das políticas públicas para agricultura familiar.

A participação em reunião e eventos do Núcleo de Estudos Agrários (NEA) do Instituto de Geociências e Ciências Exatas da UNESP, campus de Rio Claro contribuiu para o aprofundamento teórico-metodológico sobre a temática pesquisada.

Foi realizado levantamento de dados secundários sobre as principais políticas públicas para agricultura familiar tais como: Programa de Fortalecimento da Agricultura Familiar (PRONAF), Programa de Aquisição de Alimentos da Agricultura Familiar (PAA) e Programa Nacional de Alimentação Escolar (PNAE). Foram considerados os dados do Censo Agropecuário (IBGE, 2006) em especial as informações da agricultura familiar.

Realizou-se estudo avaliativo de dados secundários associado à pesquisa documental. Para os dados secundários buscaram-se informações junto à Secretária da Agricultura Familiar (SAF) do Ministério do Desenvolvimento Agrário (MDA), Companhia Nacional de Abastecimento (CONAB), Ministério do Desenvolvimento Social e Combate a Fome (MDS), Fundação Instituto de Terras do Estado de São Paulo (ITESP), Instituto Nacional de Colonização e Reforma Agrária (INCRA), Instituto de Economia Agrícola da Secretaria de Agricultura e Abastecimento do Estado de São Paulo, Instituto de Economia Agrícola do Estado de São Paulo e Secretária de Planejamento e Gestão do Estado de São Paulo.

No que diz respeito à pesquisa documental foi avaliado um conjunto de textos e relatórios do Governo Federal com ênfase nos Balanços de Avaliação da Execução do Programa de Aquisição de Alimentos 2003-2012, disponibilizados pela Secretaria de Avaliação e Gestão da Informações (SAGI), que avalia e monitora programas, projetos e serviços executados pelo MDS.

As informações e dados de origem secundária foram sistematizados em planilhas para que seus resultados fossem utilizados na elaboração de um banco de dados e na confecção de tabelas, mapas, quadros, gráficos e cartogramas, com a utilização dos softwares AutoCAD, Core Draw e Microsoft Excel. As diferentes variáveis coletadas foram especializadas por meio de mapas temáticos objetivando a caracterização e espacialização do PAA no espaço agrícola nacional do estado de São Paulo.

Os dados da execução do PRONAF em São Paulo foram obtidos junto a publicações do Banco Central do Brasil. Quanto aos assentamentos, em especial sua localização geográfica, as informações foram obtidas junto a publicações da Superintendência Regional do INCRA São Paulo e 
do ITESP. Da Secretária de Planejamento e Gestão do Estado de São Paulo obtiveram-se informações a respeito do nível de desenvolvimento das regiões administrativas paulistas.

Execução das modalidades formação de estoque e compra com doação simultânea no estado de São Paulo

De acordo com o Censo 2006, São Paulo possuía 3,5\% dos estabelecimentos familiares do país, representando 8,4\% de sua renda bruta. A Tabela 01 mostra que, a partir de 2008, São Paulo conseguiu ter uma participação no número de contratos do PAA (ou dos agricultores familiares beneficiados) bem acima de sua participação no número de agricultores familiares no País, com exceção de 2010. Já nos gastos do PAA, a participação paulista foi maior, mas com distância menor em relação à sua participação na renda bruta da agricultura familiar. Não se deve esquecer que os contratos do PAA têm um limite bastante reduzido por agricultor beneficiado e que os agricultores familiares paulistas tendem a ter maior renda per capita que os aqueles da Região Nordeste, por exemplo.

Tabela 1 - Participação de São Paulo no PAA nacional, em número de agricultores beneficiados e valor gasto, 2003-2012

\begin{tabular}{|c|c|c|c|c|c|c|}
\hline \multirow{2}{*}{ Ano } & \multicolumn{3}{|c|}{ Agricultores Beneficiados } & \multicolumn{3}{|c|}{ Gastos PAA da CONAB (RȘ) } \\
\hline & São Paulo & Brasil & $\mathrm{SP} / \mathrm{BR} \%$ & São Paulo & Brasil & SP/BR \% \\
\hline 2003 & 1.349 & 41.341 & 3,3 & $3.266,4$ & $81.541,2$ & 4,0 \\
\hline 2004 & 1.833 & 49.671 & 3,7 & $4.282,6$ & $107.185,8$ & 4,0 \\
\hline 2005 & 1.171 & 51.975 & 2,3 & $2.838,3$ & $112.791,7$ & 2,5 \\
\hline 2006 & 2.204 & 86.543 & 2,5 & $6.550,7$ & $200.667,4$ & 3,3 \\
\hline 2007 & 3.981 & 92.372 & 4,3 & $13.886,7$ & $228.353,0$ & 6,1 \\
\hline 2008 & 7.024 & 90.623 & 7,8 & $24.245,9$ & $272.929,4$ & 8,9 \\
\hline 2009 & 10.299 & 98.340 & 10,5 & $39.689,4$ & $363.381,9$ & 10,9 \\
\hline 2010 & 4.686 & 94.386 & 5,0 & $19.564,4$ & $379.735,5$ & 5,2 \\
\hline 2011 & 13.302 & 106.600 & 12,5 & $53.970,3$ & $451.036,2$ & 12,0 \\
\hline 2012 & 18.523 & 128.804 & 14,4 & $74.456,1$ & $586.567,1$ & 12,7 \\
\hline
\end{tabular}

Fonte: Elaborado pelo autor, com base nos dados da Companhia Nacional de Abastecimento, (BRASIL, 2012).

Não se tem elementos suficientes para justificar essa maior participação relativa de São Paulo em relação aos outros estados e Distrito Federal. Pode traduzir maior iniciativa de seus agricultores, bem como maior eficácia administrativa de sua superintendência regional da CONAB.

Dos 645 municípios do estado de São Paulo, em 2012, o PAA estava presente em 128 (19,8\%), atendendo 17.920 agricultores, pouco mais de 10\% dos agricultores familiares apurados no estado pelo Censo Agropecuário de 2006. Dos 128 municípios, 44 tinham Formação de Estoque e Compra com Doação Simultânea, um apenas Formação de Estoque e 83 apenas Compra com Doação Simultânea. Registrava-se que 2.319.984 pessoas eram beneficiadas pelas doações de alimentos proporcionadas pelo PAA no estado de São Paulo.

As análise e cruzamentos que serão feitos a seguir dizem respeito apenas ao ano de 2012 e aos gastos feitos diretamente pela Superintendência Regional da CONAB nas modalidades Compra com Doação Simultânea) e Formação de Estoques, as únicas que a Companhia executa em São Paulo. Em relação ao total do PAA executado em São Paulo, considerando-se também a parte sob gestão de prefeituras municipais, os gastos da CONAB representaram $80 \%$ dele.

Quanto à modalidade Formação de Estoque, apenas em 45 municípios paulistas, ou 7,0\% do total, foi encontrada essa modalidade em 2012. Dos 17.920 agricultores familiares de São Paulo contemplados pelo PAA em 2012, 4.807 (27,0\%) acessaram a Formação de Estoque, que exige maior nível de organização dos agricultores em relação à modalidade Compra com Doação Simultânea, de mais fácil execução.

A Formação de Estoque permitiu a estocagem 8,3 mil toneladas de produtos agropecuários pelos agricultores paulistas, em 2012. Predominaram, com 55\% de participação, os gêneros 
alimentícios com mínimo grau de processamento, com destaque para o feijão. Representando 36\% do valor da Formação de Estoque apareciam os alimentos com médio grau de processamento com destaque para polpa de frutas e farinha de mandioca e, com 9\%, os alimentos com alto grau de processamento, com destaque para a produção de doces. Ressalta-se que não apareceram transações vinculadas à comercialização de produtos in natura, que não podem ser estocados.

Por sua vez o acesso à Compra com Doação Simultânea foi registrado em 127 (19,7\%) dos municípios paulistas, em 2012, com 13.113 agricultores familiares sendo beneficiados, dos quais se compraram 43,8 mil toneladas de produtos agropecuários.

Os principais alimentos adquiridos foram in natura (hortaliças, frutas, tubérculos e verduras), representando 94\% das aquisições. Posteriormente, aparecem os alimentos com mínimo grau de processamento (grãos e cereais), $5 \%$ das aquisições. Alimentos com médio (polpa de frutas e farináceos) e alto grau de processamento, com destaque para doces e bebidas lácteas, representaram apenas $1 \%$ das aquisições.

A grande expressividade de alimentos in natura na modalidade Compra com Doação Simultânea se relaciona com os princípios da modalidade, que é articular a produção familiar com o atendimento direto das demandas de suplementação alimentar e nutricional de escolas, creches, abrigos, albergues, asilos, hospitais públicos e de programas sociais da localidade, como banco de alimentos, restaurantes populares, cozinhas comunitárias. Os alimentos devem ser consumidos em dias ou semanas não podendo ser estocado, atuando de forma imediata em casos de insegurança alimentar e nutricional.

Outro aspecto a ser destacado, é que a compra de alimentos in natura é mais condizente com as condições da maior parte dos agricultores familiares que, por razões financeiras e de normativas sanitárias, encontram dificuldades em investir em máquinas e equipamentos que permitissem a transformação de seus produtos.

É interessante observar que as doações encaminhadas pela CONAB para os 127 municípios com Compra com Doação Simultânea, na maior parte das vezes, não têm a produção correspondente no próprio município. Em 92 (72,4\%) deles, os produtos vieram de fora de suas fronteiras municipais e em 35 (27,6\%) de sua própria área agrícola. Isso, muito provavelmente, está relacionado com o fato de a CONAB/SP ter atuação estadual, esperando-se que quando a Compra com Doação Simultânea for executada pelo próprio município seus agricultores sejam percentualmente mais contemplados.

\section{Importância da agricultura familiar e PAA}

A Tabela 2 aponta que há sinergia entre a importância da agricultura familiar e o acesso ao PAA. Ou seja, a participação no PAA tende a crescer mais que proporcionalmente em relação à importância da agricultura familiar nos municípios.

Nota-se que aqueles municípios que têm número de agricultores familiares acima de $80,1 \%$ do total de agricultores, representam 8,5\% dos municípios paulistas e são 10,1\% dos municípios do estado com PAA. Já aqueles em que os seus agricultores familiares representam entre 60,1\% e 80,0\% de seus agricultores são 46,5\% dos municípios paulistas e 62,0\% daqueles que tem PAA. Ou seja, para essas duas faixas, a participação do PAA é maior que a participação no número de municípios paulistas, indicando que a maior importância dos agricultores familiares é respondida mais que proporcionalmente com participação no PAA. Na faixa de 40,1\% a 60,0\% de agricultores familiares, a participação no PAA é ainda significativa, embora menor que a participação no número de municípios paulistas. Onde os agricultores familiares são pouco importantes, a participação relativa no PAA é ainda mais reduzida. 
Tabela 2 - : Participação porcentual do PAA em faixas de municípios com diferentes participações da agricultura familiar/AF nos estabelecimentos agropecuários, São Paulo, 2012

\begin{tabular}{ccccc}
\hline \multirow{2}{*}{ Importância da AF (\%) } & Número & Porcentual & Número & Porcentual \\
\hline $0,0-20,0$ & 21 & $3,3 \%$ & 0 & $0,0 \%$ \\
$20,1-40,0$ & 48 & $7,4 \%$ & 3 & $3,1 \%$ \\
$40,1-60,0$ & 221 & $34,3 \%$ & 31 & $24,8 \%$ \\
$60,1-80,0$ & 300 & $46,5 \%$ & 80 & $62,0 \%$ \\
$80,1-100,0$ & 55 & $8,5 \%$ & 13 & $10,1 \%$ \\
\hline Total & 645 & $100,0 \%$ & 127 & $100,0 \%$ \\
\hline
\end{tabular}

Fonte: Elaborado pelo autor, com dados da Companhia Nacional de Abastecimento, (BRASIL, 2012) e IBGE (2006).

\section{Distribuição do PAA entre as regiões administrativas do Estado de Sāo Paulo}

Para análise da atuação do PAA no espaço agrícola paulista considerou-se a divisão políticoadministrativa da Secretaria de Planejamento e Desenvolvimento Regional do Estado de São Paulo, conforme figura 1, que estabelece a espacialização de 15 Regiões Administrativas. Além das Regiões Metropolitanas de São Paulo, existiam outras 14 regiões administrativas: Santos, São José dos Campos, Sorocaba, Campinas, Ribeirão Preto, Bauru, São José do Rio Preto, Araçatuba, Presidente Prudente, Marília, Central, Barretos e Franca. No que diz respeito a Região Administrativa de Sorocaba e Itapeva, devido as alterações recentes da Secretaria de Planejamento e Gestão do estado de São Paulo foram considerados dados conjugados, prevalecendo apenas como Região Administrativa de Sorocaba.

Figura 1 - Regiões Administrativas do Estado de São Paulo.

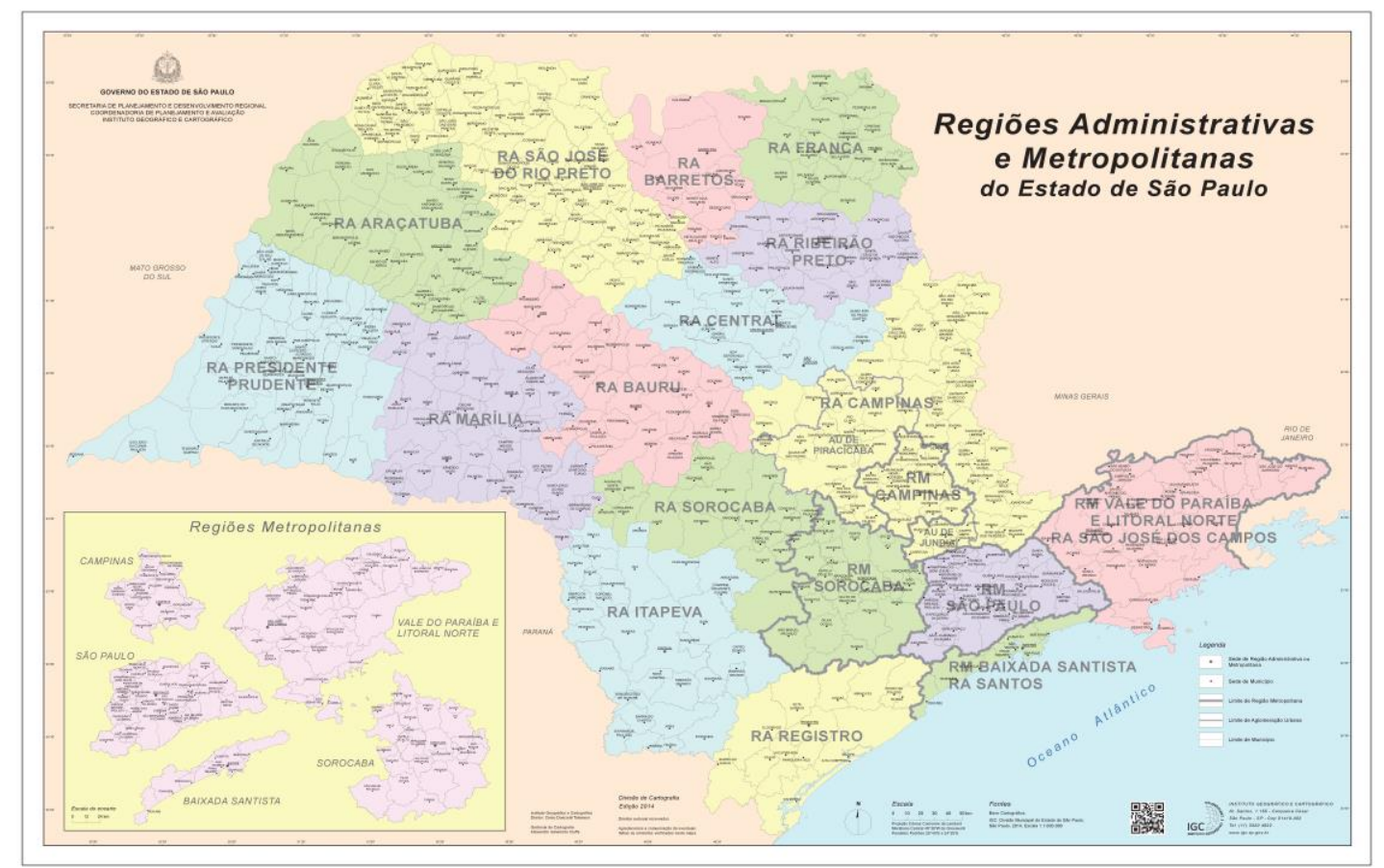

Fonte: Governo do Estado de São Paulo, Secretaria de Planejamento e Desenvolvimento Regional (SÃO PAULO, 2016). 
A Tabela 3 registra uma série de indicadores dessas regiões administrativas: populacionais, geográficos e econômicos. Quase metade da população do estado encontra-se concentrada nas 39 cidades que compõe a Região Metropolitana de São Paulo, responsável por 56,3\% do PIB paulista. Com exceção de Registro, que possui imensa área de preservação natural e nível reduzido de população, as outras regiões em torno da metrópole paulistana têm importante contribuição para a economia do estado; são elas Campinas, Sorocaba, São José dos Campos e Santos (ou Baixada Santista). A chamada macro metrópole, resultado da soma dessas cinco regiões mais a de São Paulo, concentra 85,7\% do PIB do estado de São Paulo, com forte presença nos setores secundário e terciário. As atividades agrícolas são mais bem distribuídas pelo território paulista. (Secretária de Planejamento e Gestão do Estado de São Paulo, 2015.)

Tabela 3 - Perfil das Regiões Administrativas do Estado de São Paulo, em ordem crescente de população.

\begin{tabular}{ccccccc}
\hline \multirow{2}{*}{ Região Administrativa } & \multicolumn{2}{c}{ Municípios } & \multicolumn{2}{c}{ População - 2010 } & \multicolumn{2}{c}{ PIB - 2010 } \\
& Número & \% SP & Pessoas & $\%$ SP & R S milhões & $\%$ SP \\
\hline Registro & 14 & 2,2 & 269.233 & 0,7 & $3.403,90$ & 0,3 \\
Barretos & 19 & 3,0 & 419.372 & 1,0 & $8.401,77$ & 0,8 \\
Franca & 23 & 3,6 & 705.707 & 1,7 & $12.973,01$ & 1,0 \\
Araçatuba & 43 & 6,7 & 735.401 & 1,8 & $14.813,05$ & 1,2 \\
Presidente Prudente & 53 & 8,2 & 833.120 & 2,0 & $14.340,18$ & 1,2 \\
Marília & 51 & 7,9 & 940.347 & 2,3 & $17.317,71$ & 1,4 \\
Central & 26 & 4,0 & 951.408 & 2,3 & $23.800,11$ & 1,9 \\
Bauru & 39 & 6,1 & 1.052 .395 & 2,6 & $22.299,77$ & 1,8 \\
Ribeirão Preto & 25 & 3,9 & 1.246 .046 & 3,0 & $31.965,85$ & 2,6 \\
São José do Rio Preto & 96 & 14,9 & 1.436 .300 & 3,5 & $29.065,19$ & 2,3 \\
Santos & 9 & 1,4 & 1.662 .392 & 4,0 & $47.302,46$ & 3,8 \\
São José dos Campos & 39 & 6,1 & 2.262 .135 & 5,5 & $61.698,19$ & 5,0 \\
Sorocaba & 79 & 12,5 & 2.800 .950 & 6,8 & $60.432,15$ & 4,8 \\
Campinas & 90 & 14,0 & 6.241 .314 & 15,1 & $197.034,00$ & 15,8 \\
São Paulo & 39 & 6,1 & 22.153 .766 & 47,7 & $679.592,61$ & 56,3 \\
\hline Estado São Paulo & 645 & 100,0 & 43.706 .982 & 100,0 & $1.224 .439,95$ & 100,0 \\
\hline
\end{tabular}

Fonte: Elaborado pelo autor, com base nos dados da Secretária de Planejamento e Gestão do Estado de São Paulo (2016).

São as regiões do macro metrópole, conforme o Quadro 2, que tendem a apresentar a maior renda per capita no Estado. A exceção é Sorocaba, que é superada pelas regiões Central e de Ribeirão Preto. Ao reportar ao Figura 1, pode-se entender essa situação. A região de Sorocaba é bastante grande, contendo parte muito industrializada, em torno do município, e parte mais agrícola e empobrecida, ao seu Sul, próximo a cidade de Itapeva. Muitos desses municípios, aliás, compõem o Alto Vale do Ribeira (o Médio e o Baixo encontram-se na região de Registro), com baixo índice de desenvolvimento humano. As regiões com menor renda per capita tendem a se concentrar no Sul e no oeste do estado de São Paulo. 
Quadro 2 - Regiões Administrativas paulistas classificadas de acordo com a renda per capita, em reais.

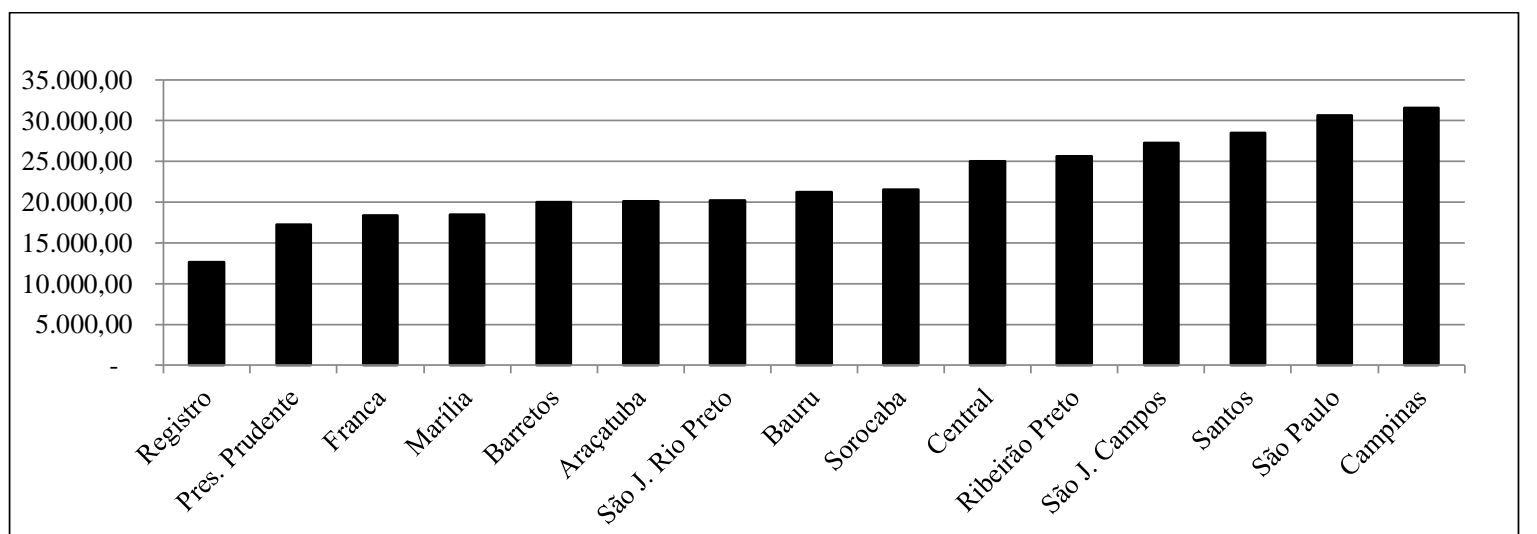

Fonte: Elaborado pelo autor, com base nos dados da Secretária de Planejamento e Gestão do Estado de São Paulo (SÃO PAULO, 2016).

Ao se analisar a distribuição das duas modalidades de PAA entre as regiões administrativas do estado, percebe-se que mais de $50 \%$ dos municípios atendidos tanto pela Compra com Doação Simultânea quanto pela Formação de Estoque estão localizados em três regiões administrativas, de Presidente Prudente, Sorocaba e Bauru. No caso de Sorocaba, a maior parte de seus municípios contemplados está situada em sua parte mais ao sul, que, insista-se, é pouco industrializada e possui baixa renda per capita. Estas três regiões têm pouco mais do que 11\% da população do Estado.

Entre as regiões mais industrializadas, Campinas aparece em quinto lugar entre as contempladas com Compra com Doação Simultânea. Contudo, pode-se perceber que sua participação no PAA é significativamente menor do que sua participação na população de São Paulo.

Parece ficar claro, portanto, que as regiões com menos população, mais pobres e mais dependentes da agricultura foram relativamente mais contempladas com a execução do PAA. Exemplo disso é Registro, com apenas 0,7\% da população estadual, mas com participação na Compra com Doação Simultânea de 5,5\% e na Formação de Estoque de 8,9\%.

Tabela 4 - Distribuição das modalidades do PAA entre regiões administrativas de São Paulo, em ordem decrescente de importância da Compra com Doação Simultânea, 2012.

\begin{tabular}{cccccc}
\hline \multirow{2}{*}{ Região Administrativa } & \multicolumn{2}{c}{ CDS Doação } & \multicolumn{2}{c}{ FE Estoque } & \% da \\
& Municípios & $\%$ & Municípios & $\%$ & População \\
\hline Presidente Prudente & 31 & 24,4 & 10 & 22,2 & 2,0 \\
Sorocaba & 24 & 18,9 & 11 & 24,4 & 6,8 \\
Bauru & 11 & 8,7 & 5 & 11,1 & 2,6 \\
São José do Rio Preto & 11 & 8,7 & 0 & 0,0 & 3,5 \\
Campinas & 10 & 7,9 & 2 & 4,4 & 15,1 \\
Marília & 9 & 7,1 & 2 & 4,4 & 2,3 \\
Registro & 7 & 5,5 & 4 & 8,9 & 0,7 \\
Araçatuba & 7 & 5,5 & 2 & 4,4 & 1,8 \\
Ribeirão Preto & 5 & 3,9 & 4 & 8,9 & 3,0 \\
São José dos Campos & 3 & 2,4 & 2 & 4,4 & 5,5 \\
São Paulo & 3 & 2,4 & 1 & 2,2 & 47,7 \\
Barretos & 2 & 1,6 & 1 & 2,2 & 1,0 \\
Franca & 2 & 1,6 & 0 & 2,2 & 1,7 \\
Central & 1 & 0,8 & 0 & 0,0 & 2,3 \\
Santos & 1 & 0,8 & 45 & 100,0 & 1,0 \\
\hline Estado São Paulo & 127 & 100,0 & & & 100,0 \\
\hline Fonte: Elaborado pelo autor, com dados da Companhia Nacional de Abastecimento, (BRASIL, 2012).
\end{tabular}


A Figura 2 apresenta a distribuição espacial da modalidade Formação de Estoque na conformação do espaço agrícola do estado de São Paulo.

Figura 2 - Municípios Vinculados a Modalidade Formação de Estoque São Paulo (2012)

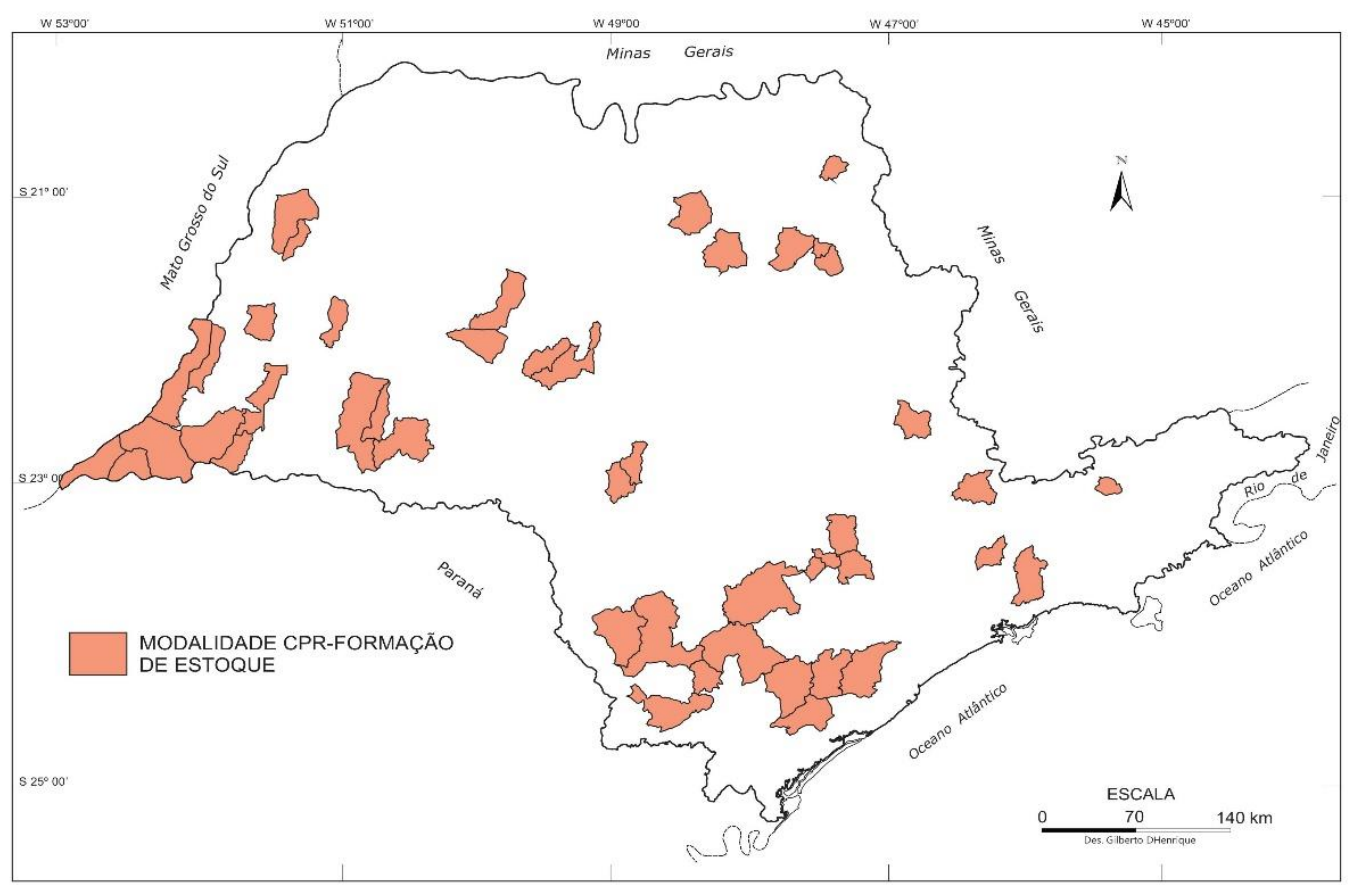

Fonte: Elaborado pelo autor, com dados da Companhia Nacional de Abastecimento, (BRASIL, 2012).

Comparando as figuras 2 e 3, percebe-se maior concentração da modalidade Formação de Estoque nas regiões administrativas de Presidente Prudente dos seus 53 municípios, $10(19,0 \%)$ estão vinculados à essa modalidade; Sorocaba dos 79 municípios da região, 11 municípios (14,0\%) estão vinculados, exatamente aqueles mais ao sul da região e; Registro - dos seus 14 municípios, 5 (36,0\%) foram contemplados com Formação de Estoque. Nestas três regiões encontravam-se 26 dos 45 municípios paulistas contemplados com a Formação de Estoques. Há poucos municípios nas regiões mais industrializadas do estado contemplados com Formação de Estoque. Por exemplo, na região de Campinas, apenas $2(1,80 \%)$ de seus 90 municípios recebem essa modalidade de PAA. Fica nítido que as regiões mais pobres, com menor PIB per capita vêm sendo mais atendidas pela modalidade Formação de Estoque.

Em relação a execução da modalidade Compra com Doação Simultânea. A figura 3 demostra a sua conformação no espaço agrícola do estado de São Paulo. 
Figura 3 - Municípios Vinculados a Modalidade Compra com Doação Simultânea São Paulo (2012)

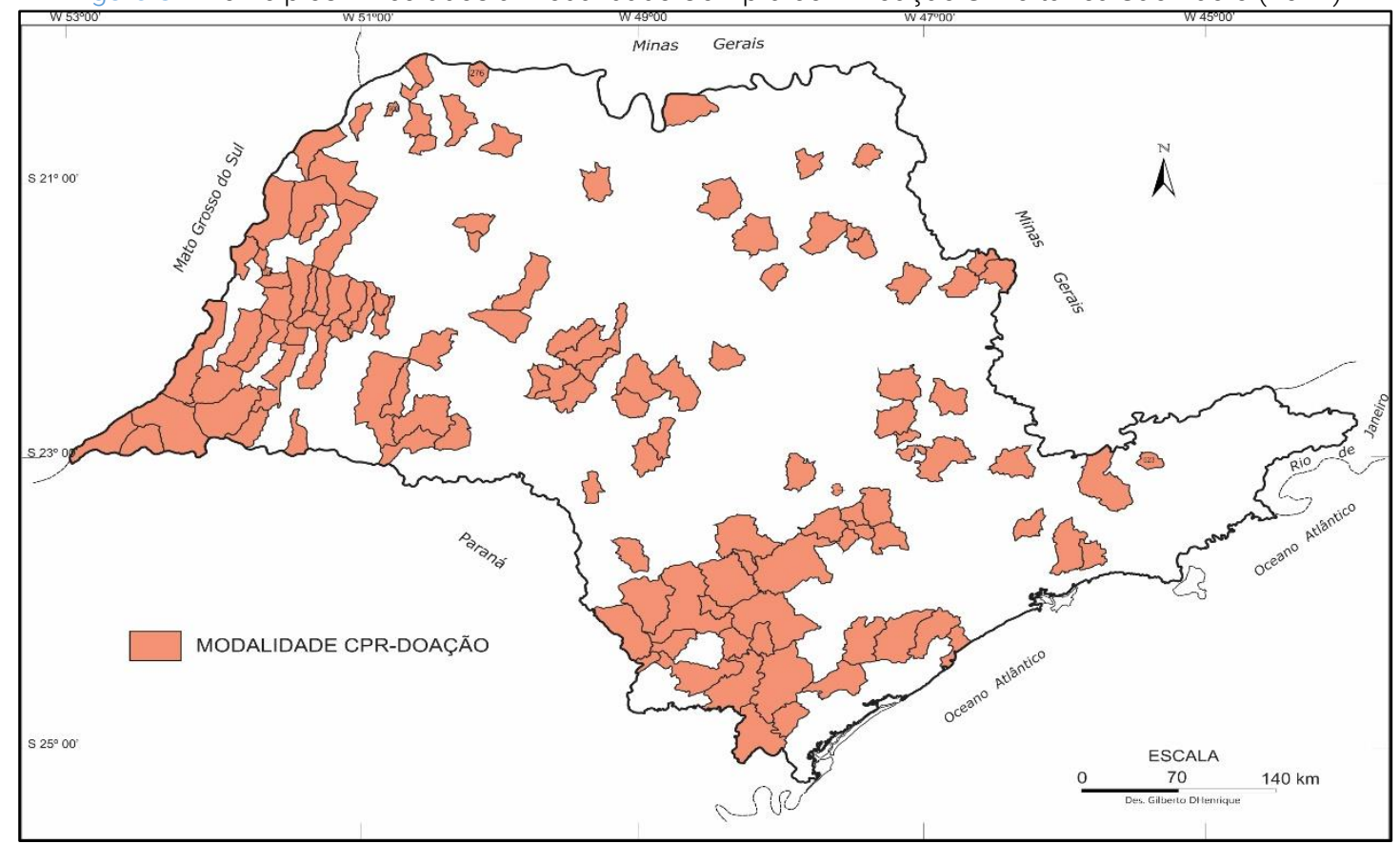

Fonte: Elaborado pelo autor, com dados da Companhia Nacional de Abastecimento, (BRASIL, 2012).

As regiões administrativas que possuem maior expressividade na modalidade Compra com Doação Simultânea são: Presidente Prudente - 31 (58,4\%) de seus municípios são contemplados com essa modalidade; Registro - sete ou metade de seus municípios são beneficiados; Sorocaba - dos seus 79 municípios, 24 (30,0\%) participam da modalidade; Bauru - 11 (28,0\%) de seus 39 municípios são contemplados; Marília - dos 51 municípios 12 (24,0\%) estão vinculados as ações da modalidade; Araçatuba - dos 43 municípios 8 (19,0\%) foram contemplados e; São José do Rio Preto - dos 96 municípios, 12 (13,0\%) estão vinculados a modalidade Compra com Doação Simultânea.

Levando em conta que a Compra com Doação Simultânea, além do efeito na renda do agricultor, procura contemplar, imediatamente, pessoas em insegurança alimentar, para quem são encaminhadas as doações de alimentos, a distribuição dessa modalidade no estado, em 2012, se mostrou corretamente vinculada àquelas regiões mais pobres do Estado, como o são Registro, Presidente Prudente e a parte sul de Sorocaba.

\section{Reforma agrária e PAA}

Outra variável concernente ao PAA é sua relação com os assentamentos localizados no estado de São Paulo. O PAA proporciona a comercialização de produtos oriundos dos assentamentos e atua na geração de renda, podendo significar avanço na estruturação e no regaste da autoestima do assentado, do respeito próprio perante uma sociedade contraditória, cujas tradições e modos de vidas nem sempre confluem com a realidade vivida por estes sujeitos.

Dos 17.920 estabelecimentos da agricultura familiar vinculados ao PAA no estado de São Paulo em 2012, 9.052 (51,0 \%) são agricultores familiares e 8.577 (48,0\%) assentados da reforma agrária. As demais categorias enquadradas no PAA (agroextrativista, pescador, quilombola e atingidos por barragens) representam 291 beneficiados (1,0\%).

No caso da modalidade Formação de Estoque, a participação dos assentados de reforma agrária é mais alta, na casa dos 59\%. Já na Compra com Doação Simultânea, 54,0\% são agricultores 
familiares, 44,0\% assentados da reforma agrária e 2,0\% quilombolas, pescadores, agroextrativistas e moradores atingidos por barragens.

É bom se dizer que dos 151.015 estabelecimentos de agricultura familiar em São Paulo levantados pelo Censo Agropecuário de 2006, apenas 6.228 se declararam como sendo assentados de reforma agrária, ou seja, apenas 4,1\% do total (BRASIL, 2009).

De forma geral, os assentamentos rurais têm, em seu dia-a-dia, a necessidade de superar as imposições do meio técnico-científico-informacional (Santos, 2012), as limitações do acesso ao crédito rural, solo improdutivo e baixa infraestrutura. Portanto, o PAA auxilia na mediação para inserir agricultores vulneráveis aos meios de comercialização.

A figura 4 foi construída com informações obtidas junto à Fundação Instituto de Terra do Estado de São Paulo (ITESP) e ao Instituto Nacional de Colonização e Reforma Agrária (INCRA) Regional São Paulo. Em 96 (15,0\%) dos municípios do estado existem assentamentos de reforma agrária, administrados por uma das duas instituições. Em alguns municípios existem mais de um assentamento.

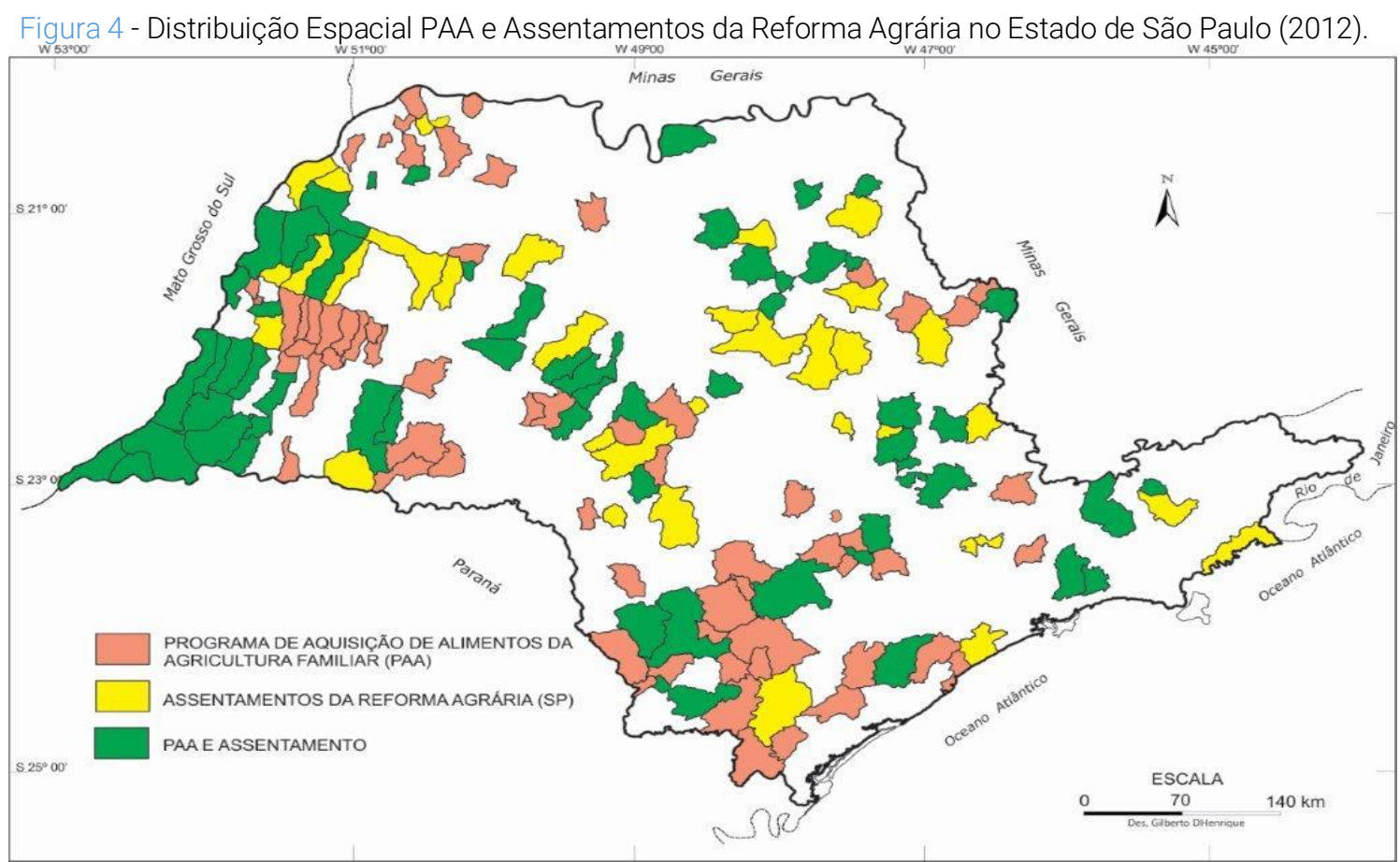

Fonte: Elaborado pelo autor, com dados da Companhia Nacional de Abastecimento, (BRASIL, 2012).

Dos municípios com assentamentos, em 61 deles ou 64,0\% também aparecem ações do PAA em 2012. Dos 549 municípios paulistas sem assentamentos, em 66 ou 12,0\% tinham PAA. Esses dados e os anteriores dessa subseção indicam forte relação entre assentamentos e execução do PAA.

A Figura 04 aponta que no chamado Pontal do Paranapanema, na região administrativa de Presidente Prudente, bem como na região de Araçatuba, especialmente em municípios como Andradina e Castilho, há forte concentração regional de assentamentos e de aplicação do PAA.

O fato dos assentados, em termos relativos, acessarem mais o PAA do que agricultores familiares já consolidados merecem maior reflexão, à procura de suas razões. Pode-se supor que os assentados teriam maior nível de organização e maior capacidade de reinvindicação, forjada nos anos de luta nos acampamentos e na conquista da reforma agrária. Outra possibilidade é que ocorre 
forte articulação entre as estruturas institucionais de reforma agrária, especialmente o INCRA, e a CONAB/SP, com suas superintendências procurando atender, em grande parte, o mesmo público com seus programas.

Ao mesmo tempo, sabe-se que a s condições médias de vida dos assentados são mais precárias do que as dos agricultores familiares, justificando que eles sejam mais contemplados relativamente com o PAA. Até é possível supor que, como o PAA garante, nas condições paulistas, um relativamente baixo valor monetário para cada contemplado, os agricultores familiares teriam menos interesse em acessar o Programa.

\section{PRONAF e PAA}

Outra variável considerada foi a relação entre as ações do PAA e as do Programa Nacional de Fortalecimento da Agricultura Familiar (PRONAF). A figura 5 permite observar que a grande maioria dos municípios paulistas possui agricultores que acessam o PRONAF.

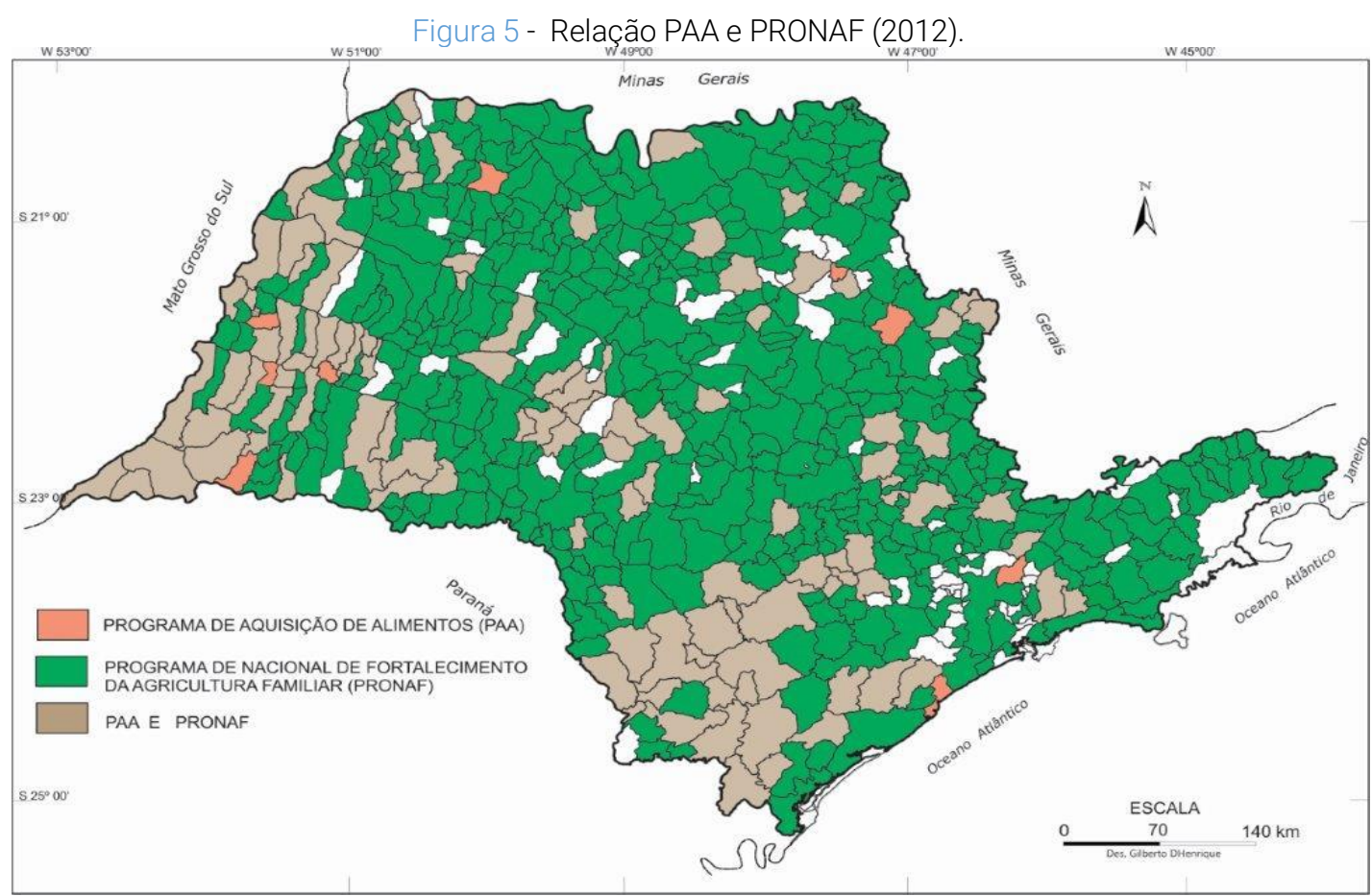

Fonte: Elaborado pelo autor, com dados da Companhia Nacional de Abastecimento, (BRASIL, 2012).

Dos 645 municípios do estado de São Paulo, 597 (93,0\%) estão vinculados ao PRONAF e 48 (7,0\%) não fazem parte. Daqueles 597 municípios, em 120 (20,0\%) seus agricultores também se utilizam do PAA. Dos 48 que não acessam o PRONAF, 7 ou 14,6\% acessam o PAA.

O grande alcance do PRONAF no Estado guarda relação com o fato de que esse Programa já tem quase 20 anos e vem, especialmente a partir de 2003, apresentando trajetória de constante crescimento em suas dotações e de estar estruturado em diferentes modalidades, contemplando agricultores familiares de diferentes realidades sociais, desde os assentados até agricultores familiares bastante tecnificados e fortemente vinculados aos mercados agropecuários.

No que diz respeito ao PAA, suas ações estão mais restritas à determinada parcela de agricultores familiares, sobretudo àqueles mais vulneráveis como, por exemplo, assentados da reforma agrária, quilombolas, ribeirinhos, agroextrativista e atingidos por barragens. 
A Tabela 5, ainda que não enfaticamente, não demonstra uma relação entre acesso ao PRONAF e ao PAA, pelo contrário. Parece que há uma substituição entre os dois programas. Assim, os municípios em que até 10,0\% de seus agricultores familiares acessam o PRONAF representam 27,1\% de todos municípios com acesso ao PRONAF e 45,0\% com acesso ao PAA. Já os municípios em que mais de $40,0 \%$ de seus agricultores acessam o PRONAF, são registrados 18,1\% dos contratos de PRONAF no Estado e $11,0 \%$ dos contratos de PAA.

Tabela 5 - Distribuição do PRONAF e PAA em grupos de municípios de acordo com o percentual de agricultores familiares que acessam o PRONAF, São Paulo, 2012.

\begin{tabular}{lccrc}
\hline \multicolumn{1}{c}{ Faixas de } & \multicolumn{2}{c}{ Contratos de Pronaf } & \multicolumn{2}{c}{ Existência do PAA } \\
\multicolumn{1}{c}{ Municípios (\%) } & Número & Porcentual & Número & Porcentual \\
\hline $0,01-10,00$ & 162 & 27,1 & 57 & 45,0 \\
$10,1-20,00$ & 168 & 28,1 & 25 & 20,2 \\
$20,1-30,00$ & 93 & 15,6 & 15 & 12,3 \\
$30,1-40,00$ & 66 & 11,1 & 7 & 11,6 \\
40,1 ou mais & 108 & 18,1 & 23 & 11,0 \\
\hline Total & 597 & 100,0 & 127 & 100,0 \\
\hline
\end{tabular}

Fonte: Brasil, (2006); Brasil, (2012). Foram excluídos municípios sem contratos do PRONAF.

Tal fato parece indicar que o PAA, na realidade paulista, vem cumprindo com um dos intentos inicialmente anunciados. Qual seja, de complementar as ações dirigidas anteriormente à agricultura familiar, em especial o PRONAF, na medida em que consegue atingir agricultores mais empobrecidos, com dificuldade de acesso ao programa de crédito. Diferentemente do PAA, o PRONAF sofre restrições do sistema bancário, com sua lógica financista, e apresenta execução mais complexa.

\section{Considerações finais}

A principal característica importante a ser destacada no PAA é o fato de os preços serem fixados previamente, não sendo possível os agricultores familiares ofertarem preços mais baixos nas chamadas públicas para compra de seus produtos. Além de garantir melhor remuneração aos agricultores beneficiados, o PAA acaba por estimular que atravessadores aumentem os preços que pagam aos agricultores familiares em mercados tradicionais.

Em relação a execução do PAA pela CONAB/SP no estado de São Paulo, pode-se perceber que o Estado tem sido relativamente mais contemplado que o conjunto de outros estados e o Distrito Federal, recebendo porcentual de recursos e número de contratos do PAA acima da participação da agricultura familiar paulista na agricultura familiar do Brasil. Dos 645 municípios paulistas, o PAA estava presente em 128 (19,8\%) em 2012. A modalidade Formação de Estoque aparecia em 45 municípios e a Compra com Doação Simultânea em 127.

Ressalta-se que o PAA apresentou maior expressividade em municípios com maior importância relativa de agricultores familiares. Também tende a se dirigir, com maior intensidade, para as regiões administrativas de São Paulo menos industrializadas e com menor renda per capita. Lugares que têm agricultores mais pobres e maior número de pessoas em insegurança alimentar.

Os municípios com assentamentos e os assentados de reforma agrária são bem mais contemplados com o PAA do que, respectivamente, os municípios sem assentamentos e os 
agricultores familiares já consolidados. Parece haver uma combinação de esforços institucionais envolvendo as superintendências regionais paulistas do INCRA e da CONAB.

Embora, neste caso, os dados não sejam tão explícitos, parece que o PAA serve como um substituto ao PRONAF, sendo que ao contrário deste Programa, o PAA atende mais fortemente agricultores mais empobrecidos e com maiores dificuldades de acesso ao sistema financeiro. Em São Paulo, a impressão que fica é que o PRONAF se organiza melhor com agricultores estruturados economicamente, enquanto o PAA fica circunscrito aos agricultores mais vulneráveis.

Levando-se em conta as intenções expressas formalmente na criação do PAA, em especial aquela de procurar atender os agricultores familiares com menor renda, as análises desse trabalho apontam que a mesma vem sendo cumprida no caso do estado de São Paulo, embora os recursos do Programa e o número de agricultores familiares ainda seja reduzido em relação ao seu público potencial.

Muitas vezes, representantes de agricultores propugnam pelo aumento do limite por agricultor do PAA, que atualmente está na casa de R\$ 8.000,00/ano. Isso deve merecer muita reflexão, não se esquecendo que tal atitude pode contribuir para atrair agricultores mais capitalizados, reduzindo o espaço dos mais pobres junto ao PAA. 


\section{Referências}

ANDRADE, M. C. de. (1979) Agricultura e capitalismo. São Paulo: Ciências Humanas, 1979. 116 p.

BACCARIN, J. G. et al. Relatório do Projeto CNPq: "Agricultura Familiar sob a Vigência da Lei Federal 11.947/2009: Abrangência e Adequação das Chamadas Públicas, Impactos na Agricultura Local e Preços Recebidos pelos Agricultores Familiares",. Documento em posse dos autores.

BACCARIN, J. G.; BUENO, G.; SILVA, D. B. P. (2014) Uso da área nos estabelecimentos agropecuários face à expansão da agroindústria canavieira no estado de São Paulo, de 1990 a 2010. In: Congresso da Sociedade de Economia, Administração e Sociologia Rural (SOBER), 52., Goiânia. Anais eletrônicos... Brasília: SOBER. Disponível em: <http://sober.org.br/congresso2014/>. Acesso em: 25 set.

BRASIL, Companhia Nacional de Abastecimento. (2012) Transparência Pública do PAA: Programa d e Aquisição de Alimentos da Agricultura Familiar.Disponível em: <http://consultaweb.conab.gov.br/c onsultas/consultatransparenciapaa.do?method=abrirConsultaMunicipio\&uf=SP>. Acesso em: 10 maio 2015.

BRASIL, Ministério do Desenvolvimento Agrário. (2015) Programa de Aquisição de Alimentos da Agric ultura Familiar (PAA). DF. Disponível em: < http://www.mda.gov.br/sitemda/secretaria/saf-

paa/modalidades-do-paa>. Acesso em: 11 nov. 2015.

BRASIL. Companhia Nacional de Abastecimento. (2012) Programa de Aquisição de Alimentos: resultados das ações da Conab em 2012. Brasília, DF. Disponível em: < http://www.conab .gov.br/OlalaCMS/uploads/arquivos/13_02_07_08_31_25_sumario_executivo_07_02_13.pdf > . Acesso em: 25 jan. 2015.

BRASIL. Lei no 10.696, de 02 de julho de 2003. (2003) Dispõe Sobre A Repactuação e O Alongamento de Dívidas Oriundas de Operações de Crédito Rural, e Dá Outras Providências. Brasili a, DF. Disponível em: <http://www.planalto.gov.br/ccivil_03/leis/2003/L10.696.htm>. Acesso em: 10 jun. 2015.

BRASIL. Lei no 11.947, de 16 de junho de 2009. (2006) Dispõe sobre o atendimento da alimentação escolar e do Programa Dinheiro Direto na Escola aos alunos da educação básica; altera as Leis nos 10.880, de 9 de junho de 2004, 11.273, de 6 de fevereiro de 2006, 11.507, de 20 de julho de 2007; revoga dispositivos Medida Provisória no 2.178/36, de 24 de agosto de 2001, e a Lei no 8.913, de 12 de julho de 1994; e dá outras providência s. Brasília, DF, 2009. Disponível em: < http://www.planalto.gov.br/ccivil_03/_ato2007 2010/2009/lei/l 11947.htm> Acesso em: 12 jun. 2015.

CORÁ, M. A. J.; BELIK, W. (Orgs). (2012) Projeto Nutre SP: análise da inclusão da agricultura familiar na alimentação escolar no estado de São Paulo. São Paulo: Instituto Via Pública. 104 p.

GRAZIANO DA SILVA, J. (1981) Modernização dolorosa: estrutura agrária, fronteira agrícola e trabalhadores rurais no Brasil. Rio de Janeiro: Zahar Editores. 192 p.

HESPANHOL, R. A. de M. (2000) Perspectivas de análise e inserção na microrregião geográfica de presidente prudente. Tese (Doutorado em Geografia). Departamento de Instituto de Geociências e Ciências Exatas, Universidade Estadual Paulista "júlio de Mesquita Filho", Rio Claro, 254 p.

Instituto Brasileiro de Geografia e Estatística IBGE. (2007) Censo Agropecuário de 2006. Rio de Janei ro. Disponível em: <http://www.ibge.gov.br/home/estatistica/economica/agropecuaria/censoagro/ 2006/agropecuario.pdf>. Acesso em: 13/07/2015.

MARAFON, G. J. (1988) Constituição do Complexo Agroindustrial e a Modernização da Agricultura: o caso do município de Marau-RS. 1988. Dissertação (mestrado) - Curso de Geografia. IGCE, Universidade Estadual Paulista "Júlio de mesquita filho", Rio Claro. 123 p. 
NEGRI NETO, C.; Paulo J.; MOREIRA, I. R. de O. (1993) divisão regional agrícola e região administrativa do estado de São Paulo: histórico, semelhança, diferença. São Paulo: Instituto de Economia Agrícola. 44 p. Disponível em: <ftp://ftp.sp.gov.br/ftpiea/tec20693.pdf>. Acesso em: 10 jul. 2015.

SÃO PAULO, Secretaria de Planejamento e Desenvolvimento Regional. Coordenadoria de Planejamento e Avaliação. (2014) Regiões Administraivas e Metropolitanas do Estado de São Paulo. 2014. Disponível em: <http://www.igc.sp.gov.br/produtos/mapas_ra.aspx?>. Acesso em: 10 nov. 2016. 